\title{
Lymphatic and haematopoietic cancer mortality in a population attending school adjacent to styrene-butadiene facilities, 1963-1993
}

\author{
Jeanne E Loughlin, Kenneth J Rothman, Nancy A Dreyer
}

\begin{abstract}
Study objective-To evaluate the risk of mortality from lymphatic and haematopoietic cancers and other causes among students.

Design-The study used school records, yearbooks, and Texas Department of Health records for the school years 1963-64 to 1992-93 to construct a cohort of 15403 students. Three mortality databases were searched to identify deaths, and mortality rates in the cohort were compared with mortality rates from the United States and Texas. Computed standardised mortality ratios and $95 \%$ confidence intervals were used.

Setting-Eastern Texas high school adjacent to facilities that have been producing synthetic styrene-butadiene since 1943.

Main results-338 deaths were identified. The all causes standardised mortality ratio was 0.84 (95\% confidence intervals $0.74,0.95)$ for men and $0.89(0.73,1.09)$ for women. The standardised mortality ratio for all lymphatic and haematopoietic cancers was $1.64(95 \%$ confidence intervals $0.85,2.87)$ for men and $0.47(0.06,1.70)$ for women. The slight male excess in lymphatic and haematopoietic cancers was stronger among men who attended school for two years or less.

Conclusions-The overall mortality from lymphatic and haematopoietic cancer among the students was little different from that of the United States as a whole. A moderate excess for men, predominantly among the shorter-term students, was offset by a deficit among women. These variations are compatible with random fluctuations; the overall pattern is not indicative of an effect of environmental exposure sustained while attending the high school.

(F Epidemiol Community Health 1999;53:283-287)
\end{abstract}

Epidemiology

Resources Inc, Newton

Lower Falls, MA

02462-1450, USA

J E Loughlin

K J Rothman

N A Dreyer

Correspondence to: Jeanne E Loughlin.

Accepted for publication 8 December 1998 plants that primarily produced styrenebutadiene or butadiene. ${ }^{1-6}$

Unfortunately, no data exist on specific environmental exposures to school students or faculty. Nevertheless, out of concern for the students' health, the Texas Department of Health conducted a retrospective cohort mortality study of female graduates of the high school and three comparison high schools from the classes of $1963-64$ to $1977-78 .^{7}$ That study found no excess of lymphatic and haematopoietic cancer. The present study extends the Texas Department of Health study by including men, including students who graduated after 1978, and continuing the follow up to 1995. Lacking data on individual student exposure to styrene or butadiene monomers, we compared the mortality of students at the school with that of the general population for selected categories of cause of death, and we compared the experience of students who attended the high school for differing lengths of time.

\section{Methods}

We constructed a preliminary roster of students by creating a database of the names of all the seniors pictured or listed in the Port Neches-Groves High School yearbooks for the school years 1963-64 to 1992-93. We assigned students a unique identification number that reflected their actual or intended graduation year. We reviewed the records of all students who had attended the school and added to the roster all students whose name we did not already have recorded from the yearbooks.

We included only those students who attended the high school for at least three consecutive months during a school year within the study period. Similarly, we considered any student who completed three consecutive months of school in any given academic year to have attended the school for that academic year. As instructed by the United States Department of Education and as required under the Family Educational Rights and Privacy Act (FERPA), we abstracted from school records only that information designated as "directory information": student name, date of birth, and years attended the school. We also abstracted all recorded name changes, such as those resulting from adoptions or marriage during high school. In accordance with FERPA, we were not allowed to record sex or Social Security number (SSN). The initial eligible cohort comprised 15553 former students of the high school. 
Table 1 Selected SMRs and 95\% confidence intervals by sex, compared with US standard rates

\begin{tabular}{|c|c|c|c|c|c|c|c|c|}
\hline \multirow[b]{2}{*}{ Cause of death } & \multicolumn{4}{|l|}{ Men } & \multicolumn{4}{|c|}{ Women } \\
\hline & $\mathrm{Obs}$ & $\operatorname{Exp}$ & $S M R$ & $95 \% C I$ & Obs & $\operatorname{Exp}$ & $S M R$ & $95 \% C I$ \\
\hline All causes & 241 & 287.72 & 0.84 & $0.74,0.95$ & 97 & 108.51 & 0.89 & $0.73,1.09$ \\
\hline All malignant neoplasms & 31 & 25.50 & 1.22 & $0.83,1.73$ & 13 & 25.18 & 0.52 & $0.28,0.88$ \\
\hline Ca digestive organs, peritoneum & 5 & 3.96 & 1.26 & $0.41,2.94$ & 2 & 2.52 & 0.80 & $0.10,2.87$ \\
\hline Ca bronchus, trachea, lung & 5 & 3.43 & 1.46 & $0.47,3.40$ & 1 & 2.25 & 0.44 & $0.01,2.48$ \\
\hline Ca breast & 0.00 & 0.02 & 0.00 & $0,164.92$ & 4 & 6.81 & 0.59 & $0.16,1.50$ \\
\hline Ca all lymphatic, haematopoietic & 12 & 7.30 & 1.64 & $0.85,2.87$ & 2 & 4.24 & 0.47 & $0.06,1.70$ \\
\hline Hodgkin's disease & 2 & 1.37 & 1.46 & $0.18,5.28$ & 1 & 0.83 & 1.20 & $0.03,6.68$ \\
\hline Leukaemia, aleukaemia & 6 & 3.30 & 1.82 & $0.67,3.96$ & 1 & 2.24 & 0.45 & $0.01,2.48$ \\
\hline Ca all other lymphopoietic & 4 & 1.95 & 2.05 & $0.56,5.26$ & 0 & 0.86 & 0.00 & $0,4.29$ \\
\hline All other malignant neoplasms & 3 & 2.65 & 1.13 & $0.23,3.31$ & 0 & 1.78 & 0.00 & $0,2.08$ \\
\hline Benign neoplasms & 5 & 0.80 & 6.27 & $2.04,14.63$ & 1 & 0.64 & 1.56 & $0.04,8.71$ \\
\hline All heart disease & 13 & 22.72 & 0.57 & $0.31,0.98$ & 6 & 7.40 & 0.81 & $0.30,1.77$ \\
\hline Ischaemic heart disease & 7 & 13.06 & 0.54 & $0.22,1.11$ & 3 & 2.80 & 1.07 & $0.22,3.13$ \\
\hline All other heart disease & 6 & 7.63 & 0.79 & $0.29,1.71$ & 3 & 3.46 & 0.87 & $0.18,2.53$ \\
\hline All external causes of death & 147 & 172.22 & 0.85 & $0.72,1.00$ & 56 & 45.80 & 1.22 & $0.92,1.59$ \\
\hline Accidents & 104 & 112.40 & 0.93 & $0.76,1.12$ & 36 & 29.88 & 1.21 & $0.84,1.67$ \\
\hline Motor vehicle accidents & 79 & 73.67 & 1.07 & $0.85,1.34$ & 30 & 22.86 & 1.31 & $0.89,1.87$ \\
\hline All other accidents & 25 & 38.74 & 0.65 & $0.42,0.95$ & 6 & 7.02 & 0.85 & $0.31,1.86$ \\
\hline Suicides & 26 & 35.81 & 0.73 & $0.47,1.06$ & 10 & 8.94 & 1.12 & $0.54,2.06$ \\
\hline Homicides & 17 & 24.01 & 0.71 & $0.41,1.13$ & 10 & 6.98 & 1.43 & $0.69,2.64$ \\
\hline AIDS & 28 & 20.35 & 1.38 & $0.91,1.99$ & 0 & 1.48 & 0.00 & $0,2.50$ \\
\hline
\end{tabular}

To obtain data on sex and name changes that occurred after leaving high school, we accessed several ancillary data sources. Computerised birth records for the years 1942-1980 maintained by the Texas Department of Health provided sex for $73 \%$ of the students in our cohort. For the students for whom we did not find a match in the birth records, we had two independent assessors assign sex based on the student's name and yearbook pictures. We were unable to assign sex to three students who did not have a picture in any yearbook and had sexual neutral names.

To identify name changes, we purchased a copy of the Texas Department of Health marriage database for the years 1966 (the first year available) to 1994 . Our intent was to ascertain possible married names for female students to improve our ability to identify deaths that might have occurred later in life. We searched the marriage database using the names of the women in the eligible cohort who had complete dates of birth and the three people with unknown sex. Our matching algorithm identified one or more marriages and the resulting married names for 5154 (68\%) of the women searched. We then conducted a second round of matching in the marriage database using as a starting point the married names picked up in the first round of matching. We found 838 additional matches. Upon completion of the school record review and the linking with the Texas marriage database, we had a total of 15722 possible last names for the 7591 women in the eligible cohort.

We used three mortality databases for vital status searching: the National Death Index, the Social Security Administration Death Master Files, and the Texas Department of Health death database. The National Death Index included nearly all United States deaths from 1979 to 1994; the Social Security Administration files included United States deaths reported to the Administration from the early 1930s to 1995; the Texas death database included reported Texas deaths for the years 1964 to 1978 . We submitted a total of 23366 records for mortality searching, which were all of the possible names for the 15408 unique cohort members who had a complete date of birth. We reviewed the results of the mortality searches and requested copies of death certificates for possible matches from the appropriate states. To be considered a correct match, the name (maiden or married name), date of birth and state of birth on the death certificate had to match the information in the cohort database. In some cases a comparison of the parents' names was required to confirm the death match for a woman who had married more than once or may have been divorced. A certified nosologist coded all causes of death and underlying cause of death according to the version of the International Classification of Diseases $(\mathrm{ICD})^{8}$ in effect at the time of death.

From the original cohort of 15553 students we eliminated 145 with unknown date of birth, two with incongruous dates of birth, and three with unknown sex. A total of 15403 students remained in the final analytic cohort.

For comparison we used United States and Texas mortality rates derived from United States National Center for Health Statistics data. The rates were stratified by sex, five year age categories, and five year calendar intervals from 1950-1992. We applied the 1990-92 rates to cohort members followed up in 1993. As the student body at the high school has been historically almost exclusively white, we used mortality rates for whites. We used the Occupational Mortality Analysis Program (OCMAP) ${ }^{9}$ to summarise person time and calculate standardised mortality ratios (SMRs) for all causes of death as well as for selected categories of death, including the lymphatic and haematopoietic cancers. We conducted all analyses using the underlying cause of death from the death certificate.

\section{Results}

We identified 338 graduates (241 men, 97 women) who had died. The 7882 men and 7521 women in the analytic cohort contributed a total of 310254 person years during the follow up period of 1963 to 31 December 1995. Table 1 shows the SMRs for all causes and for 


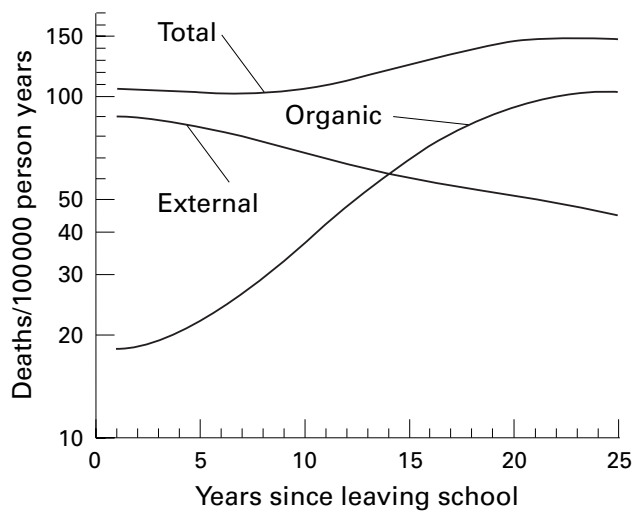

Figure 1 Trend in external and organic death rates by years since leaving school. Organic deaths comprise all except those resulting from external causes. Death rate curves are smoothed by Savitzky-Golay polynomial least squares. ${ }^{10}$

specific causes of death, compared with the United States population, adjusting for sex, age, and calendar time. The all causes SMR is $0.84(95 \%$ CI $0.74,0.95)$ for men and 0.89 (95\% CI 0.73, 1.09) for women.

Not unexpectedly, the majority of deaths in this relatively young cohort (the oldest members being approximately 50 years old at the end of follow up) were attributable to external causes. For men $147(61 \%)$ of 241 deaths were because of external causes and for women 55 (57\%) of 97 deaths. The proportion of deaths caused by external causes, compared with organic illness, decreased with years since leaving school (fig 1).

The SMRs for all cancers compared with the US population were, for men, $1.22(95 \% \mathrm{CI}$ $0.83,1.73)$ and for women 0.52 (95\% CI 0.28 , $0.88)$. The SMRs for individual cancer sites in table 1 vary considerably; the number of observed cases is small for individual cancer sites, and the associated confidence intervals are wide. The SMR for men for all lymphatic and haematopoietic cancers was 1.64 (95\% CI $0.85,2.87)$. For women the corresponding SMR was 0.47 (95\% CI 0.06, 1.70). For both sexes combined, the SMR was 1.21 (95\% CI $0.66,2.04)$. There was an unexpected excess of deaths from benign neoplasms; the SMR was 6.27 (95\% CI 2.04, 14.63) for men and 1.56
KEY POINTS

- There was a moderate excess of deaths from lymphatic and haematopoietic cancer among men, but a deficit among women.

- Students who remained in high school for three or more years experienced less subsequent mortality than those who attended school for less than three years.

- Attending school adjacent to a styrenebutadiene facility did not seem to increase the risk of subsequent mortality from lymphatic and haematopoietic cancer.

(95\% CI 0.04, 8.71) for women. For both sexes combined, the SMR for benign neoplasms was 4.18 (95\% CI $1.53,9.09)$.

We conducted additional analyses by subgroup according to the number of years of attendance at the high school $(\leqslant 2$ years at the school and $\geqslant 3$ years, table 2). The SMR for all causes of death among men who attended the school for $\leqslant 2$ years was $1.42(95 \%$ CI 1.11 , $1.80)$, while that for men who remained in school for $\geqslant 3$ years was 0.72 (95\% CI 0.61 , 0.83).

Among men who attended the high school for $\leqslant 2$ years, the greatest relative increase in mortality from lymphatic and haematopoietic cancers was for those dying of leukaemia and aleukaemia. This category includes lymphoid leukaemia; myeloid leukaemia; monocytic leukaemia; other specified leukaemias such as acute erythraemia, erythroleukaemia, and megakaryocytic leukaemia; and leukaemias of unspecified cell type. The corresponding ICD codes are in the range 204.0 to 208.9. Although there are some slight increases in risk seen among other groups and for other categories of lymphatic and haematopoietic cancers, the numbers are too small and the corresponding confidence intervals too wide to draw conclusions regarding these subcategories. In general, men who remained in school longer faced smaller relative increases in mortality from lymphatic and haematopoietic cancers. We found a similar pattern for deaths resulting from external causes. Among men who attended the school for $\leqslant 2$ years a large

Table 2 Selected SMRs and 95\% confidence intervals by years of attendance at Port Neches-Groves High School, compared with US standard rates, men only

\begin{tabular}{|c|c|c|c|c|c|c|}
\hline \multirow[b]{2}{*}{ Cause of death } & \multicolumn{3}{|c|}{$\leqslant 2$ years $(n=1530)$} & \multicolumn{3}{|c|}{$\geqslant 3$ years $(n=6352)$} \\
\hline & Obs/Exp & $S M R$ & $95 \% C I$ & $O b s / \operatorname{Exp}$ & $S M R$ & $95 \% C I$ \\
\hline All causes & $71 / 49.89$ & 1.42 & $1.11,1.80$ & $170 / 237.83$ & 0.72 & $0.61,0.83$ \\
\hline All cancer & $9 / 4.27$ & 2.11 & $0.96,4.00$ & $22 / 21.24$ & 1.04 & $0.65,1.57$ \\
\hline $\mathrm{Ca}$ all lymphatic, haematopoietic & $4 / 1.25$ & 3.20 & $0.87,8.20$ & $8 / 6.05$ & 1.32 & $0.57,2.60$ \\
\hline Lymphosarcoma, reticulosarcoma & $0 / 0.12$ & 0.00 & $0.00,31.89$ & $0 / 0.57$ & 0.00 & $0.00,6.43$ \\
\hline Hodgkin's disease & $0 / 0.23$ & 0.00 & $0.00,15.75$ & $2 / 1.13$ & 1.77 & $0.21,6.38$ \\
\hline Leukaemia, aleukaemia & $3 / 0.57$ & 5.29 & $1.09,15.46$ & $3 / 2.73$ & 1.10 & $0.23,3.21$ \\
\hline Ca all other lymphopoietic & $1 / 0.33$ & 3.01 & $0.08,16.76$ & $3 / 1.62$ & 1.86 & $0.38,5.43$ \\
\hline Benign neoplasms & $1 / 0.14$ & 7.35 & $0.18,40.94$ & $4 / 0.66$ & 6.05 & $1.65,15.48$ \\
\hline All heart disease & $4 / 3.73$ & 1.07 & $0.29,2.75$ & $9 / 18.99$ & 0.47 & $0.22,0.90$ \\
\hline All external causes of death & $48 / 30.35$ & 1.58 & $1.17,2.10$ & $99 / 141.88$ & 0.70 & $0.57,0.85$ \\
\hline Accidents & $34 / 19.66$ & 1.73 & $1.20,2.42$ & $70 / 92.74$ & 0.76 & $0.59,0.95$ \\
\hline Motor vehicle accidents & $25 / 12.95$ & 1.93 & $1.25,2.85$ & $54 / 60.72$ & 0.89 & $0.67,1.16$ \\
\hline All other accidents & $9 / 6.72$ & 1.34 & $0.61,2.54$ & $16 / 32.02$ & 0.50 & $0.29,0.81$ \\
\hline Suicides & $9 / 6.39$ & 1.41 & $0.64,2.68$ & $17 / 29.42$ & 0.58 & $0.34,0.93$ \\
\hline Homicides & $5 / 4.30$ & 1.16 & $0.38,2.72$ & $12 / 19.71$ & 0.61 & $0.32,1.06$ \\
\hline AIDS & $4 / 3.58$ & 1.12 & $0.30,2.86$ & $24 / 16.77$ & 1.43 & $0.92,2.13$ \\
\hline
\end{tabular}


proportion of their excess mortality was from motor vehicle accidents.

For women the analyses by number of years of attendance show a slightly increased SMR $1.64(95 \%$ CI $1.14,2.29)$ for death from any cause among those women who attended school for $\leqslant 2$ years. As with men this increased risk is accounted for mainly by excess deaths attributable to external causes. Among women who remained in school for $\geqslant 3$ years we found fewer deaths than expected for these same categories of death.

We also examined mortality by year of graduation, dividing the cohort into those who graduated or were scheduled to graduate before 1980 and from 1980 forward. We found no clear pattern. We repeated all analyses using the state of Texas as the comparison population, with little difference in the results.

\section{Discussion}

Port Neches-Groves High School alumni had overall mortality rates that were slightly lower than those of the United States as a whole. Follow up of women in a record linkage study such as this, where we lacked Social Security number, can be problematic because women are likely to change their names. To evaluate success of follow up among women, we can compare the SMR for overall mortality among women with that of men. We assume that no biological reason exists to increase or depress overall mortality to any considerable extent for only one sex among students of the high school. The study hypothesis relates to a cause of death that is but a small proportion of overall deaths, and should not measurably affect the overall mortality. Thus, overall mortality serves as an indirect evaluation of adequacy of follow up. We observed an overall SMR for women (0.89) that was higher than the overall SMR for men (0.84). This finding implies that the follow up for women was comparable with that of men, and thus indicates that the steps we took to find married names or other aliases for female students resulted in a follow up for women that was satisfactory. The small difference between the observed SMRs for total mortality and 1.0 could be because of some underascertainment of deaths in the cohort, or to real differences between the cohort and the population data, or some combination of these factors.

The excess of deaths attributable to benign neoplasms was an incidental finding. All six who died of benign neoplasms had brain tumours. In their cohort study, Divine and Hartman $^{1}$ reported six deaths from benign neoplasms among butadiene workers, with 3.8 expected. They found no apparent trend with duration of employment. Although Delzell et al did not mention benign neoplasms in their published report, ${ }^{5}$ their interim data indicate a total of nine deaths from benign neoplasms in their overall cohort, with 11 expected. ${ }^{6}$ Meinhart et $a l^{2}$ and Matanoski et $a l^{\beta}$ do not present findings on deaths from benign neoplasms.

The mortality rate in this cohort for lymphatic and haematopoietic cancer was little different from that of the United States as a whole; from US death rates, we would have expected about 11.5 deaths, slightly less than the 14 we observed. The moderate excess of male deaths was partially offset by a deficit among women. These variations for men and women may be just random fluctuations, as the numbers are small and subject to substantial statistical variability. Another possibility is that the excess in men stems from occupational exposures sustained after leaving school. An effect from exposure that occurred while attending high school should not have been limited to men; thus, the deficit in deaths from lymphatic and haematopoietic cancer among women is not consistent with an environmental effect on students while they were attending school.

This conclusion is reinforced by the analysis comparing short-term male students with longer term male students. The observed excess in lymphatic and haematopoietic cancer deaths among men is stronger for men who attended the high school for no more than two years $(\mathrm{SMR}=3.2$, based on four observed deaths $v 1.25$ expected) than for men who attended the school for three or more years $(\mathrm{SMR}=1.3$, based on 8 observed deaths $v 6.05$ expected). This difference by length of attendance at school is also not consistent with an environmental effect.

A weakness of the study is that we had to evaluate cancer mortality rather than incidence. Neither Texas nor neighbouring Louisiana had statewide tumour registries during the follow up period of this study. In addition, Port Neches is a small, rural community, and residents with serious disease seek diagnosis and treatment in other locations, such as Houston, Galveston, and Baton Rouge. Therefore it was not feasible to assess cancer incidence in the cohort with any hope of achieving the same degree of follow up that we achieved from the three separate mortality sources that we used.

Another weakness of the study is the lack of direct environmental measurements of styrene or butadiene in the school. The close proximity of the school to the plants would presumably have resulted in some environmental exposure from plant emissions, but these would be expected to be less concentrated than occupational exposures experienced by plant workers. Another difference between this study and studies of occupational exposure is the younger age of the population that we studied. Little is known about how age at exposure might influence any potential carcinogenic effect.

Three retrospective cohort studies ${ }^{1-3}$ and one nested case-control study ${ }^{4}$ have evaluated the mortality of workers employed in styrenebutadiene or butadiene monomer manufacturing. All three cohort studies found lower than expected mortality rates for all causes of death combined and all cancers combined. A combined analysis of the three cohort studies (using an interim report of one of the studies ${ }^{11}$ ) reported 36 cases of leukaemia with 34.2 expected, for an SMR of 1.05 (95\% CI 0.74, 1.46)..$^{11}$

Nevertheless, increased death rates from certain lymphopoietic cancers have been re- 
ported for some subgroups of employees exposed to styrene-butadiene. Among butadiene workers, Divine and Hartman found an excess of lymphosarcoma deaths (9 observed/ 4.7 expected). ${ }^{1}$ The increase was concentrated among men with less than five years of employment, first hired during the second world war, and employed in a job with the potential for varied amounts of butadiene exposure on a routine basis. There was no appreciable leukaemia excess (13 observed/ 11.5 expected).

The results of the one case-control study of styrene-butadiene workers, conducted by Santos-Burgoa et $a l^{4}$ within the cohort studied by Matanoski et $a l,{ }^{3}$ are inconsistent with the findings in the three cohort studies, including the very cohort that formed the source population for the case-control study. Santos-Burgoa et al reported a seven to ninefold increased rate of leukaemia mortality among employees exposed to butadiene. ${ }^{4}$ In the same study, little association between leukaemia and styrene remained after the association with butadiene was taken into account. The remarkable discrepancy between the null result for leukaemia reported for the same population by Matanoski et $a l^{\beta}$ and the strong relation found in this case-control study prompted serious concern regarding the validity of these results. ${ }^{12} 13$

A fourth cohort study, recently completed, assessed the mortality of 15649 men employed at eight North American styrene-butadiene plants during the period 1943-1991.5 The study improved upon some shortcomings of the previous studies with its large size, long follow up period, use of objective classifications of exposure indices, and evaluation of mortality patterns by employment factors such as payroll status, duration of employment, time since hire, work location, and estimated cumulative exposure to styrene and butadiene monomer. The authors found a small to moderate increase in deaths from leukaemia for the overall group of styrene-butadiene industry workers (48 observed/37 expected). The excess was concentrated among "ever hourly" subjects with $10+$ years worked and $20+$ years since hire and among subjects in three job classifications with potential for high exposure to butadiene or styrene monomers. The authors inferred that the associations between employment factors and forms of lymphatic and haematopoietic cancer other than leukaemia were not causal.
To summarise, the conflicting evidence from occupational mortality studies of styrenebutadiene workers raised concern that students who attended a high school that borders a styrene-butadiene plant were at increased risk for certain haematopoietic cancers. Our long term follow up of these students indicates that their mortality rates from these cancers does not indicate any important increased risk for the cancers in question. We did find an unexpected increase in deaths from benign neoplasms.

We thank Ms Galina Savikovsky and Ms Rita Tsang for their programming support. We are grateful to the staff at Port Neches-Groves High School for their help and encouragement.

Funding: this study was funded by a group of styrene-butadiene manufacturers including: BASF Corporation, Chevron Chemical Company, Conoco Inc, The Dow Chemical Company, Exxon Company, USA, Goodyear Tire and Rubber Co, Mitsubishi, Canadian OXY Offshore Production Company, PetroTex, Phillips Petroleum Company, Quantum Chemical Corporation, Solutia Inc, Texaco, Inc, Texas Petrochemicals Corporation, Union Carbide Corporation, and Uniroyal Goodrich Tire Company. This study was conducted under a contract that, at the outset, guaranteed the investigators the unfettered right to publish the results.

Conflicts of interest: none.

1 Divine BJ, Hartman CM. Mortality update of butadiene production workers. Toxicology 1996;113:169-81.

2 Meinhardt TJ, Lemen RA, Crandall MS, et al. Environmental epidemiologic investigation of the styrene-butadiene rubber industry. Mortality patterns with discussion of the rubber industr. Mortion Environ Health 1982;8:250-9.

3 Matanoski GM, Santos-Burgoa C, Schwartz L. Mortality of a cohort of workers in the stryrene-butadiene polymer a cohort of workers in the stryrene-butadiene polymer Perspect 1980;86:107-17.

4 Santos-Burgoa C, Matanoski GM, Zeger S, et al. Lymphohematopoietic cancer in styrene-butadiene polymerization workers. Am F Epidemiol 1992;136:843-54.

5 Delzell E, Sathiakumar N, Hovinga M, et al. A follow-up tudy of synthetic rubber workers. Toxicology 1996;113: $182-9$.

6 Delzell E, Sathiakumar N, Macaluso M, et al. A follow-up study of synthetic rubber workers. Houston, TX: International Institute of Synthetic Rubber Producers, Inc, October 2, 1995.

7 Donelson RK. Female mortality from lymphatic and hematopoietic neoplasm in a high school near industrial plants producing styrene butadiene rubber, 1964-1978. Austin, TX: Texas Department of Health, July 8, 1980.

8 World Health Organization (WHO). Manual of the international statistical classification of diseases, injuries, and causes national statistical classification of
of death. Geneva: WHO, 1977.

9 Marsh G, Preininger M. A user-oriented occupational cohort mortality analysis program. Am Stat 1980;34: $245-6$.

10 Savitzky A, Golay MJE. Smoothing and differentiation of data by simplified least squares procedures. Anal Chem 1964;36:1627-39

11 Divine BJ, Wendt JK, Hartman CM. Cancer mortality among workers at a butadiene production facility. In: Sorsa $\mathrm{M}$, Feltonen $\mathrm{K}$, Vainio $\mathrm{H}$, et al, eds. Butadiene and styrene: assessment of health hazards. IARC scientific publications no 127. Lyons: IARC, 1993.

12 Cole P, Delzell E, Acquavella J. Exposure to butadiene and lymphatic and hematopoietic cancer. Epidemiology 1993;4: 96-103.

13 Acquavella JF. The paradox of butadiene epidemiology. Exp Pathol 1989;37:114-18. 